\title{
PREVALÊNCIA DE GARDNERELLA VAGINALIS, CANDIDA SPP. E TRICHOMONAS VAGINALIS EM EXAMES CITOPATOLÓGICOS DE GESTANTES ATENDIDAS NO HOSPITAL UNIVERSITÁRIO DE SANTA MARIA-RS
}

\author{
Gabriela Bonfanti \\ Thissiane de Lima Gonçalves
}

\begin{abstract}
RESUMO
Introdução: Durante a gestação podem ocorrer distúrbios no mecanismo fisiológico do trato genital, composto por Lactobacillus spp., resultando em processos infecciosos determinados por agentes bacterianos. Tais infecções podem levar a doença pélvica inflamatória, parto prematuro e infecção fetal, sendo que o exame de Papanicolaou pode sugerir a presença desses agentes infecciosos. Objetivo: Verificar a prevalência dos agentes microbiológicos encontrados no Papanicolaou de gestantes atendidas no HUSM. Métodos: Foi realizado um levantamento do arquivo dos laudos citológicos do Laboratório do Hospital Universitário de Santa Maria (HUSM) no período de janeiro de 2005 a dezembro de 2008, das gestantes que realizaram o exame citopatológico durante o pré-natal. Resultados: Foram analisados 1344 laudos e observou-se que $59,82 \%$ das pacientes apresentaram flora bacteriana normal, ou seja, composta por Lactobacillus spp. O total de floras alteradas foi de 40,17\%. Dessas, 38,24\% apresentaram Gardnerella vaginalis, 33,75\% Candida spp., 5,92\% Trichomonas vaginalis, 21,54\% flora mista (cocos e outros bacilos) e 0,54\% outros microorganismos como Leptothrix vaginalis e Fuseobacterium spp. Conclusão: Essas infecções estão associadas à complicações na gestação e nossos resultados mostraram uma alta prevalência de agentes patogênicos nas pacientes, confirmando a importância do acompanhamento pré-natal das gestantes para o diagnóstico e tratamento adequado dessas possíveis infecções.
\end{abstract}

Descritores: Gestantes; Exame citopatológico; Agentes microbiológicos.

\section{PREVALENCE OF GARDNERELLA VAGINALIS, CANDIDA SPP. E TRICHOMONAS VAGINALIS IN CITOPATOLOGIC TESTS OF PREGNANT WOMEN ATTENDED IN UNIVERSITY HOSPITAL OF SANTA MARIA- RS}

\begin{abstract}
Introduction: During pregnancy may occur disorders in the physiological mechanism of genital tract, consisting of Lactobacillus spp., resulting in infectious processes determined by bacterial agents. These infections can lead to pelvic inflammatory disease, preterm delivery and fetal infection. The Pap Smear test may suggest the presence of these infectious agents. Objective: To determinate the prevalence of microbiological agents found in the Pap smear test of pregnant women attending in HUSM. Methods: It was made survey of the file of the cytological laboratory of the Hospital Universitario de Santa Maria (HUSM) from January 2005 to December 2008, belonging to women, who underwent the examination of cytopathologic during prenatal care. Results: 1344 reports were analyzed and indicated that $59.82 \%$ of patients showed normal bacterial flora, which is composed of Lactobacillus spp. The total flora switched was $40.17 \%$. Of these, $38.24 \%$ had Gardnerella vaginalis, 33.75\% Candida spp., 5.92\% Trichomonas vaginalis, 21.54\% mixed flora (bacilli and cocci) and $0.54 \%$ other microorganisms such as Leptothrix vaginalis and Fuseobacterium spp. Conclusion: The microbial infections are associated with complications during pregnancy, our results showed a high prevalence of pathogens in patients, confirming the importance of prenatal care of pregnant women for diagnosis and proper treatment of possible infections.
\end{abstract}

Descriptors: pregnant women, cervical screening, microbiological agents. 


\section{INTRODUÇÃO}

O equilíbrio do ecossistema vaginal é mantido por complexas interações entre a flora vaginal dita normal, os produtos do metabolismo microbiano, o estado hormonal e a resposta imune do hospedeiro' ${ }^{1}$. O mecanismo fisiológico de defesa do trato genital feminino mais importante contra vaginites é a microbiota lática, caracterizada pela presença de lactobacilos (bacilos de Döderlein), que constituem um grupo heterogêneo de bactérias encontradas nas secreções cérvico-vaginais e, na sua maioria, correspondem a Lactobacillus acidophilus ${ }^{2}$. A população lactobacilar na vagina cresce devido a um aumento de estrógenos que, consequentemente, fazem o glicogênio se acumular nas células que revestem a vagina. Os lactobacilos convertem o glicogênio em ácido lático e o pH da vagina torna-se ácido (3,8 a 4,5). O predomínio de Lactobacillus spp., capazes de produzir $\mathrm{H}_{2} \mathrm{O}_{2}$ e ácido lático, contribui para a inibição do crescimento de vários microrganismos nocivos à mucosa vaginal. A gestação, juntamente com outros fatores como o uso de contraceptivos orais e eliminação da flora normal por antibióticos, causa um distúrbio desse ecossistema podendo levar à inflamação da vagina $^{3}$. Estes processos inflamatórios podem ser acompanhados por processos infecciosos determinados por agentes microbiológicos, sendo mais comuns os determinados por inversão da flora vaginal normal, caracterizando a Vaginose Bacteriana (VB), e os desencadeados por Candida spp. e Trichomonas vaginalis ${ }^{4}$.

A VB foi originalmente descrita por Gardner \& Dukes, $1955^{5}$, como uma vaginite não específica caracterizada por secreção vaginal acinzentada, de odor fétido, com $\mathrm{pH}$ mais elevado que o normal, tendo como principal agente causal a Gardnerella vaginalis ${ }^{2}$. Em gestantes, tem sido relacionada a vários efeitos desfavoráveis a gravidez, incluindo endometrites, doenças pélvicas inflamatórias, trabalho de parto e parto prematuro, e endometrites pós-parto ${ }^{6}$. Ainda o microrganismo característico da VB pode ascender do baixo trato genital feminino através da cérvice, resultando em infecção fetal ${ }^{7}$. Admite-se que a flora vaginal com $\mathrm{VB}$ produza toxinas que tornam algumas mulheres mais suscetíveis a iniciarem a cascata de citocinas e prostaglandinas que desencadeiam o trabalho de parto8. Admite-se, inclusive, a possibilidade da produção de proteases pelos microorganismos que compõem a VB, determinando a rotura das membranas e iniciando o trabalho de parto prematuramente9.

A candidíase vaginal é uma entidade causada por um fungo oportunista, do gênero Candida, dimorfo, de comportamento saprofídico no trato genital inferior, que sob determinadas condições se multiplica excessivamente, tornando-se patogênico. A espécie Candida albicans responde por $80 \%$ a $90 \%$ das infecções ${ }^{10},{ }^{11}$.

Até $40 \%$ de mulheres grávidas possuem espécies de Candida na flora vaginal, uma taxa duas vezes maior do que a encontrada em mulheres não-grávidas. Deve-se isso ao aumento dos níveis circulantes de estrogênios e deposição de glicogênio e outros substratos na vagina durante a gestação. Ao contrário da infecção por Trichomonas e da Vaginose Bacteriana, a colonização por Candida na gravidez não é frequentemente associada com um aumento do risco de parto prematuro, mas há algumas evidências emergentes que a erradicação da Candida na gravidez pode reduzir o risco de parto prematuro e aborto $\operatorname{tardio}^{12}$. Ainda, o microrganismo pode infectar o feto durante a gestação ou no parto, podendo se manifestar na forma de colonização oral pelas leveduras, conhecida como sapinho, ou como candidíase cutânea congênita, podendo ainda ocorrer invasão sistêmica geralmente pulmonar do microrganismo ${ }^{13}$.

Outra infecção que frequentemente afeta o trato genital feminino durante a gestação é a tricomoníase. $\mathrm{O}$ Trichomonas vaginalis não possui forma cística, apresentando apenas a forma trofozoítica. Em condições normais, quando o $\mathrm{pH}$ da vagina é ácido (em torno de 3,8 a 4,5) o desenvolvimento desse microorganismo não é propício. No entanto, durante a gestação, quando ocorre um aumento do $\mathrm{pH}$ vaginal (em torno de 5,5 a 5,8) esse desenvolvimento é facilitado ${ }^{14}$. É de grande importância o reconhecimento da tricomoníase na gestação, já que a sua presença está frequentemente associada à presença de outras infecções que produzem infecção neonatal ou puerperal. Também, estudos demonstram que pacientes com infecção por Trichomonas vaginalis apresentam probabilidade maior de sofrerem ruptura prematura de 
membranas e, consequentemente parto prematuro, do que pacientes com outros patógenos genitais. Ainda, existem relatórios de pneumonia neonatal associada a esse protozoário ${ }^{15}$ podendo o contágio ocorrer durante o parto, descrito em $5 \%$ dos recém-nascidos ${ }^{16}$.

Em cinco estudos coorte, T. vaginalis foi associado com ruptura prematura de membranas ${ }^{17}$, parto prematuro ${ }^{18}$, baixo peso ao nascer entre mulheres com ruptura espontânea de membranas ${ }^{19}$, e baixo peso ao nascer e parto prematuro ${ }^{20}$.

Muito embora o exame de Papanicolaou tenha sido preconizado, fundamentalmente, para $\mathrm{o}$ reconhecimento das alterações epiteliais de natureza neoplásica ou pré-neoplásica do colo uterino, por meio dele, apesar de não ser o ideal, pode-se sugerir, com alta correlação aos testes considerados como padrão ouro, a presença de certo agentes infecciosos ${ }^{21}, 22$. Dessa forma, a identificação morfológica ou a suspeição diagnóstica de determinados vírus e bactérias são informes adicionais do exame citopatológico ${ }^{23}$ como é o caso da Vaginose Bacteriana e infecções por Trichomonas vaginalis e Candida spp.

Tendo em vista a relevância de tais infecções em pacientes gestantes, o objetivo desse estudo é determinar a prevalência de infecções por Gardnerella vaginalis, Trichomonas vaginalis e Candida spp. nos exames citopatológicos realizados por essas pacientes durante o pré-natal no Hospital Universitário de Santa Maria para que o tratamento das mesmas possa ser realizado, evitando, assim, complicações da gestação e prejuízos à saúde do recém-nascido.

\section{MATERIAIS E MÉTODOS}

Realizou-se um estudo quali-quantitativo e retrospectivo em 1344 Laudos Citopatológicos do Ambulatório de Obstetrícia do Hospital Universitário de Santa Maria (HUSM) - Santa Maria, RS, no período de janeiro de 2005 a dezembro de 2008. A população estudada foi composta por mulheres grávidas, que realizaram o exame citopatológico (Papanicolaou) durante o pré-natal no HUSM.

\section{RESULTADOS}

Dos 1344 laudos de gestantes analisados, observou-se que $59,82 \%$ das pacientes apresentaram flora bacteriana normal, ou seja, composta por Lactobacillus spp. O total de floras vaginais alteradas, isto é, apresentando um ou mais microorganismos potencialmente patogênicos foi de 40,18\% (Figura 1).

FIGURA 1- Distribuição da flora vaginal detectada nos exames citopatológicos de gestantes atendidas no HUSM no período de janeiro de 2005 a dezembro de 2008.

\section{Floras bacterianas}

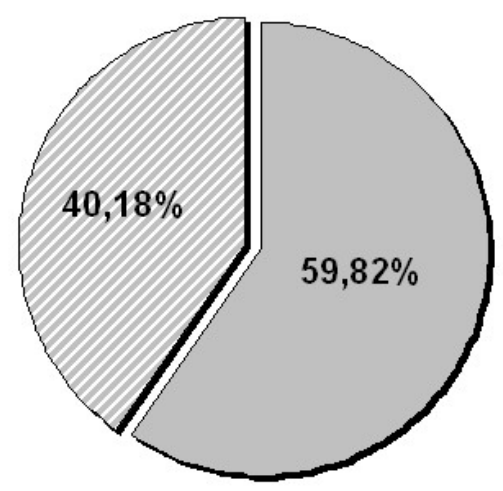

$\square$ Normal

$\square$ Altera da

Dentre as floras vaginais alteradas, encontradas em 557 pacientes, 38,24\% apresentaram Gardnerella vaginalis, 33,75\% Candida spp., 5,92\% Trichomonas vaginalis, $21,54 \%$ flora mista, composta por cocos e outros bacilos, e $0,54 \%$ outros microorganismos como Leptothrix vaginalis e Fusobacterium spp. (Tabela 1).

Em 3,05\% das floras alteradas, representando 17 laudos de pacientes, encontrou-se infecção mista, ou seja, composta por mais de um microorganismo potencialmente patogênico (Tabela 2).

Alguns microorganismos ainda foram encontrados juntamente com flora bacteriana mista, composta por cocos e bacilos. Do total das 33 pacientes infectadas por Trichomonas vaginalis, 21 delas (63,64\%) apresentaram flora bacteriana mista associada. Do mesmo modo, dentre as 188 pacientes que apresentaram hifas de Candida spp., 45 (29,94\%) delas também apresentaram flora bacteriana mista associada. 
Tabela 1- Distribuição dos microrganismos potencialmente patogênicos detectados nos exames citopatológicos de gestantes atendidas no HUSM no período de janeiro de 2005 a dezembro de 2008

\begin{tabular}{ccc}
\hline & $\mathrm{n}$ & $\%$ \\
\hline Gardnerella vaginalis & 213 & 38,24 \\
Candida spp. & 188 & 33,75 \\
Trichomonas vaginalis & 33 & 5,92 \\
Mista* & 120 & 21,54 \\
Outras** & 03 & 0,54 \\
\hline Total & 557 & 100,00 \\
\hline
\end{tabular}

* Flora mista é constituída por cocos e outros bacilos.

**Outros microorganismos incluem Leptothrix vaginalis e Fusobacterium spp.

Tabela 2 - Infecções mistas detectadas nos exames citopatológicos de gestantes atendidas no HUSM no período de janeiro de 2005 a dezembro de 2008

\begin{tabular}{ccc}
\hline & $\mathrm{N}$ & $\%$ \\
\hline Gardnerella vaginalis + Trichomonas vaginalis & 2 & 10,52 \\
Candida spp. + Trichomonas vaginalis & 5 & 26,31 \\
Candida spp. + Gardnerella vaginalis & 10 & 63,16 \\
\hline Total & 17 & 100,00 \\
\hline
\end{tabular}

\section{DISCUSSÃO E CONCLUSÃO}

A flora vaginal humana saudável na idade reprodutiva é composta predominantemente por espécies de lactobacilos. Seus produtos metabólicos, como peróxido de hidrogênio $\left(\mathrm{H}_{2} \mathrm{O}_{2}\right)$, ácido lático e bacteriocinas são responsáveis pelo importante papel de manter a flora vaginal normal pela inibição da colonização de outros patógenos ${ }^{24}$. Estudos têm demonstrado que, além do $\mathrm{pH}$ vaginal e da presença de lactobacilos, polipeptídios catiônicos antimicrobianos e antivirais ${ }^{25}$, linfócitos $\mathrm{T}$, células "natural killer", e células apresentadoras de antígenos (macrófagos e células dendríticas), presentes em maior número na cérvice uterina, principalmente na zona de transformação, são extremamente importantes na defesa da mucosa vaginal e cervical contra infecções microbiológicas ${ }^{26}$.

No presente trabalho, $59,82 \%$ das pacientes apresentaram no exame de Papanicolaou o perfil de flora bacterina normal, e esse é constituído por bacilos de Doederlein, no entanto o aparecimento de infecções vulvovaginais é freqüentemente evidenciada na gestação.

O microorganismo prevalente encontrado nos exames citopatológicos de gestantes foi a Gardnerella vaginalis, representando $38,24 \%$ das floras vaginais alteradas. Tal microorganismo pode colonizar assintomaticamente o trato genital feminino ou provocar Vaginose Bacteriana (VB), que é diagnosticada quando três dos quatro seguintes critérios estiverem presentes: $\mathrm{pH}$ vaginal maior que 4,5; presença de "clue cells" ou células-alvo no fluído ou esfregaços vaginais; leucorréia fluída, cinza ou branca; ou teste com $\mathrm{KOH}$ positivo ${ }^{27}$, o qual evidencia a presença de flora anaeróbia presente na vagina.

A VB é considerada uma vaginite inespecífica, pois não é associada com sinais de inflamação, como fluido vaginal leucocitário28. Embora o corrimento seja o sintoma mais freqüente, $50 \%$ das mulheres com VB são completamente assintomáticas ${ }^{29}$. A infecção resulta de mudanças na microbiota vaginal normal, causando um aumento dos organismos anaeróbios, e uma diminuição dos Lactobacillus spp., sendo muito comum em mulheres na idade reprodutiva ${ }^{30}$ e em $15 \%$ a $20 \%$ das mulheres grávidas ${ }^{31}$.

Estudos demonstram uma evidente associação entre essa condição de VB e complicações durante a gravidez, como parto prematuro, corioamnionite, endometrite pós-parto, complicações pós-parto para o recém-nato e infecções após procedimentos 
ginecológicos, como histerectomia ${ }^{32}, 33$, além de um possível aumento do risco para contrair o vírus da imunodeficiência humana (HIV) ${ }^{34}$. A VB durante a gestação tem efeito de ruptura sobre o meio cérvico vaginal normal, podendo contribuir para ruptura prematura de membranas e trabalho de parto prematuro. São raras as infecções neonatais, porém frequente a bacteremia pós-parto, na gestantes, por Gardnerella vaginalis ${ }^{15}$. A associação da VB com o parto prematuro pode ser reforçada pela evidência de que 30 a $40 \%$ dos partos prematuros apresentam alguma evidência de infecção subclínica intra-uterina ${ }^{27}$.

A infecção por essa bactéria tem sido associada a fatores sócio-culturais como idade, falta de educação sexual adequada, grau de escolaridade e ocupação, que acabam por se refletir em atitudes relacionadas a maus hábitos de higiene, como grande número de parceiros, início precoce da vida sexual ativa, principalmente associada à falta de uso de preservativos ${ }^{35}$.

Embora alguns autores concluam que $\mathrm{O}$ rastreamento para VB assintomática durante o pré-natal e seu tratamento nos casos positivos é um método eficaz para reduzir de maneira significativa o trabalho de parto prematuro ${ }^{36}$, o tratamento da vaginose bacteriana, a fim de prevenir o parto prematuro, através da administração de agentes antimicrobianos em mulheres grávidas, não tem sido efetivo ${ }^{37},{ }^{38}$. Existem várias explicações para isso e uma delas é que o parto prematuro é uma síndrome e essa infecção é somente uma das causas ${ }^{31}$. Outra, é que combater os microorganismos mais prevalentes na VB não garante a recolonização do meio vaginal pelos Lactobacillus spp., produtores de peróxido de hidrogênio ${ }^{39}$ que normalizariam o meio cérvico vaginal.

O microrganismo Candida spp. foi o segundo microrganismo encontrado com maior frequencia nas gestantes, presente em $33,75 \%$ das floras vaginais alteradas. No entanto, a simples presença de Candida spp. no conteúdo vaginal não equivale à existência de doença, visto que $25 \%$ a $40 \%$ das mulheres com cultura positiva são completamente assintomáticas 40 , pois ao colonizar o trato genital é evidenciada na cultura. Segundo Cavalcant, Miranda e Portugal, $2005^{40}$, a Candida spp. raramente é isolada em mulheres pré-menárquicas ou na pós-menopausa, sugerindo uma dependência hormonal para a ocorrência da infecção, devido ao aumento da quantidade de glicogênio, principalmente no período pré-menstrual e gestação.

A candidíase geralmente ocorre durante o último trimestre de gravidez e suas manifestações clínicas incluem prurido intenso, irritação, secreção vaginal aquosa ou espessa e tenaz, podendo conter partículas esbranquiçadas, além de sensação de ardência, inclusive ao urinar, que deve ser resultante de escoriações por coçar ou por outros irritantes, além de disuria e dispareunia ${ }^{29}$.

A infecção pode ser adquirida pelo feto durante a gestação ou no parto. Durante as primeiras semanas de vida, os recém-nascidos podem apresentar colonização oral por leveduras, provavelmente adquiridas durante a passagem pelo canal de parto e pela ingestão de partículas do conteúdo vaginal. Aproximadamente $20 \%$ dos neonatos apresentam monilíase, conhecida como sapinho. A Candidíase Cutânea Congênita é atualmente conhecida como a forma mais freqüente adquirida congenitamente e está associada algumas vezes à invasão sistêmica pulmonar. Essa forma da infecção corresponde a uma manifestação na pele do recém-nascido, ocasionada por infecção intra-uterina pela Candida albicans, caracterizando-se pela presença de pústulas ou bolhas e exantema maculopapular disseminado ${ }^{13}$.

Ainda, a meningite por Candida spp. pode acometer principalmente recém-nascidos pré-termo, ocasionando seqüelas permanentes e alta mortalidade. Outras doenças como endocardite, pneumonia e peritonite podem ser causadas pela Candida albicans, levando à graves consequências para o recémnascido ${ }^{41}$.

Alguns pesquisadores tem empregado o exame citopatológico no rastreamento dessas infecções pelo excelente detalhamento morfológico dado pela coloração de Papanicolaou ${ }^{42}$. No entanto, para Wied, $1998^{43}$, a identificação específica dos fungos nem sempre é possível nos esfregaços citológicos, posto que se pode relatar a presença de vários elementos fragmentados das hifas ou pseudo-hifas, e/ou pequena quantidade de esporos, sendo a cultura o método mais sensível para detecção do fungo em conteúdo vaginal. 
Em relação à associação de leveduras a outros agentes, no presente estudo, apenas 5 pacientes $(0,92 \%$ das floras vaginais alteradas) apresentaram infecção concomitante por Trichomonas vaginalis e Candida spp. Do mesmo modo, a associação entre Candida spp. e Gardnerella vaginalis foi encontrada em 10 pacientes (1,85\% das floras alteradas). Essas associações são pouco freqüentes, e isso se deve ao $\mathrm{pH}$ em que esses microorganismos se desenvolvem. Apesar de o fungo Candida ocorrer tanto em pH ácido como alcalino, é mais comumente encontrada em $\mathrm{pH}$ ácido, enquanto a Gardnerella vaginalis e o Trichomonas vaginalis desenvolvem-se principalmente em $\mathrm{pH}$ alcalino.

A vaginite pelo Trichomonas vaginalis é uma infecção transmitida quase exclusivamente nas relações sexuais. O período de incubação é de 4 a 28 dias, podendo o parasita infectar a vagina, uretra ou bexiga ${ }^{15}$, provocando fluído vaginal abundante, espumoso, verdeamarelado ou claro e fétido, prurido vulvar intenso, ardência e vulvite, disúrias e poliaciúrias e desconforto perineal ${ }^{44}$.

No presente estudo, 5,92\% das gestantes que possuíam flora vaginal alterada estavam infectadas por Trichomonas vaginalis. $\mathrm{O}$ microorganismo coloniza o trato urogenital de mulheres, preferindo o epitélio escamoso da vagina, porém tendo sido isolado também em punção supra púbica, do reto e das trompas de Falópio. As complicações associadas à tricomoníase em mulheres incluem: 1 - aumento da transmissão e infectividade do HIV; 2 - grande risco de infertilidade tubal e doença inflamatória pélvica atípica; 3 - aumento do risco de câncer cervical; 4 - aumento do risco de infecções pós-operatórias, e 5 - associação com parto prematuro $^{45}$.

A transmissão vertical ocorre em cerca de $5 \%$ das gestações $^{46}$. Recém-nascidos do sexo feminino, de mães com tricomoníase vaginal podem desenvolver tricomoníase sintomática ou assintomática ${ }^{47}$. A infecção usualmente regride no neonato com a diminuição da influência dos hormônios sexuais maternos, mas o tratamento é apropriado se a infecção dura mais de um mês. Abortos assintomáticos ocorrem, mas estima-se que um terço das mulheres irão desenvolver sintomas dentro de 6 meses, e atualmente entre 50 a $90 \%$ tornam-se sintomáticas se não tratadas.
O tratamento de grávidas com tricomoníase assintomática não previne $\mathrm{o}$ trabalho de parto prematuro e pode ser nocivo para o bebê, por isso, a triagem rotineira seguida de tratamento em grávidas assintomáticas não está recomendada ${ }^{46}$.

A citologia cervical usando Papanicolaou tem uma sensibilidade de 60 a $70 \%$ de identificação de Trichomonas vaginalis, comparada à cultura ${ }^{7}$, que é considerada o método padrão ouro. Ainda, a infecção por esse microorganismo pode prejudicar o diagnóstico de lesões pré-malignas como células escamosas atípicas de significado indeterminado (ASC-US) ou mesmo de LSIL/HPV, por causar um processo inflamatório que leva a um aumento do volume nuclear, halo perinuclear, bi- ou multinucleação e ainda disceratose ${ }^{48}$.

A respeito do envolvimento do Trichomonas vaginalis no câncer cervical, as opiniões são divergentes. Alguns autores acreditam que este parasita é um agente causador de uma simples inflamação, outros, por sua vez, levantam a possibilidade desse parasita ser um agente etiológico de lesões prémalignas e possível evolução para câncer cervical ${ }^{49}$.

As floras consideradas mistas encontradas nos laudos analisados são compostas por cocos e bacilos. Essa situação foi evidenciada em $21,54 \%$ das floras alteradas e, embora não cause nenhum dano quando encontrada isolada, a presença desses microorganismos no meio cérvico vaginal pode propiciar $o$ desenvolvimento de outros microorganismos potencialmente patogênicos, pois altera o $\mathrm{pH}$ da sua faixa de normalidade. No presente estudo, $29,94 \%$ das pacientes com presença de Candida spp. e 63,64\% das pacientes infectadas por Trichomonas vaginalis também apresentavam flora bacteriana mista, exemplificando essa condição.

Assim, nesse estudo detectou-se uma prevalência significativa de aproximadamente $40 \%$ de agentes potencialmente patogênicos na flora vaginal de gestantes atendidas no Hospital Universitário de Santa Maria. Isso demonstra que as alterações hormonais ocorridas no período gestacional alteram o equilíbrio microbiano local e propiciam o desenvolvimento de alguns microorganismos como Gardnerella vaginalis, Candida spp. e Trichomonas vaginalis. Esses dados 
reforçam a importância do acompanhamento pré-natal das gestantes, por meio do exame citopatológico (Papanicolaou) para que essas infecções sejam detectadas e tratadas evitando danos à mãe e ao feto ou neonato.

\section{REFERÊNCIAS BIBLIOGRÁFICAS}

1 - Giraldo PC, Gonçalves AKS, Moreno Linhares I, Cornetta MCM, Giraldo HPD. Patologia do trato genital inferior. la ed. São Paulo: Roca, 2005.

2 - Oliveira EH, Soares LF. Prevalência de vaginites infecciosas através da citologia clínica: um estudo no laboratório central de saúde pública do Piauí. Rev Bras Anal Clin. 2007; 39(1): 33-5.

3 - Tortola GJ, Funke BR, Case CL. Microbiologia. 8a ed. Porto Alegre: Artmed, 2005.

4 - Ribeiro AA, Oliveira DF, Sampaio MCN, Carneiro MAS, Tavares SBN, Souza NLA et al. Agentes microbiológicos em exames citopatológicos: estudo de prevalência. Rev Bras Anal Clin. 2007; 39(3): 179-81.

5 - Gardner HL, Dukes CD. Haemophilus vaginalis vaginitis: a newly defined specific infection previously classified as non-specific vaginitis. Am J Obstet Gynecol. 1955; 69: 962-76.

6 - Nelson DB, Bellamy S, Nachamkin I, Ness RB, Macones GA, Allen-Taylor L. First semester bacterial vaginosis, individual microorganism levels, and risk of second trimester pregnancy loss among urban women. Fertil Steril. 2007; 88(5): 1396-1403.

7 - Hay PE. Bacterial vaginosis and miscarriage. Curr Opin Infect Dis. 2004; 17(1): 41-44.

8 - Morris M, Nicoll A, Simms I, Wilson J, Catchpole M. Bacterial vaginosis: a public health review. BJOG. 2001; 108(5): 439-450.

9 - Martius J, Eschenbach DA. The role of bacterial vaginosis as a cause of amniotic fluid infection, chorioamnionitis and prematury - a review. Arch Gynecol Obstet. 1990; 247(1): 1-13.

10 - Zamith R, Baracat EC, Nazário ACP, Nicolau SM. Corrimento genital. In: Prado, F.C.; Ramos, J.; Valle, J.R. Atualização terapêutica. 18a ed. São Paulo: Artes Médicas, 1997.
11- Mattos AHS, Bonamigo C, Pina LAV, Silva JRM. Prevalência de leveduras do gênero Candida em secreção vaginal. Rev bras ginecol obstet. 1993; 15(4): 163166.

12 - Hay P, Czeizel AE. Asymptomatic trichomonas and candida colonization and pregnancy outcome. Best Pract Res Clin Obstet Gynaecol. 2007; 21(3): 403-409.

13 - Heredia MS, Gomperdetz O. Candidíase. In: Farhat, C.K.; Carvalho, E.S.; Carvalho, L.H.F.R.; Succi, R.C.M. Infectologia Pediátrica. 1a ed. São Paulo: Atheneu, 1994.

14 - Consolaru ME, Suzuki LE, Marques EBA. Estudo da tricomoníase e a sua abordagem no diagnóstico colpocitológico. Rev Bras Anal Clin. 1999; 31(1): 25-28.

15 - Lee R.V. Infecções transmitidas sexualmente. In: Burrow, G.N.; Ferris, T.F. Complicações crônicas durante a gravidez. 4a ed. São Paulo: Roca. 1996.

16 - Kruse W. Vulvovaginites e cervicites. In: Freitas, F.; Menke, C.H.; Rivoire, W. Rotinas em Ginecologia. 2a ed. Porto Alegre: Artes Médicas Sul. 1993.

17 - Minkoff H, Grunebaum AN, Schwarz RH, Feldman J, Cummings M, Crombleholme $\mathrm{W}$ et al. Risk factors for prematurity and premature rupture of membranes: a prospective study of the vaginal flora in pregnancy. Am J Obstet Gynecol. 1984; 150(8): 965-972.

18 - Meis PJ, Goldenberg RL, Mercer B, Moawad A, Das A, Mcnellis D el al. The preterm prediction study: significance of vaginal infections. Am J Obstet Gynecol. 1995; 173(4): 1231-1235.

19 - Riduan JM, Hillier SL, Utomo B, Wiknjosastro G, Linnan M, Kandum, N. Bacterial vaginosis and prematurity in Indonesia: association in early and late pregnancy. Am J Obstet Gynecol. 1993; 169(1): 175-178.

20 - Hardy PH, Nell EE, Spence MR, Hardy JB, Graham DA, Rosenbaum RC. Prevalence of six sexually transmitted disease agents among pregnant inner-city adolescents and pregnancy outcome. Lancet. 1984; 324(8398): 333-337.

21 - Adad SJ, Lima RV, Sawan ZTE, Silva MLG, Souza MAH, Saldanha JC et al. Frequency of Trichomonas vaginalis, Candida sp. and Gardnerella vaginalis in cervical-vaginal smears in four different decades. Sao Paulo Med J. 2001; 16(4): 200-205. 
22 - Motta EV, Fonseca AM, Bagnoli VR, Ramos L, Pinotti JA. Colpocytology in a preventive gynecological ambulatory service. Rev Assoc Med Bras. 2001; 47(4): 302-310.

23 - Forsum U, Jakobsson T, Larsson PG, Schmidt H, Beverly A, Bjørnerem B et al. An international study of the interobserver variation between interpretations of vaginal smear criteria of bacterial vaginosis. Acta Pathol Microbiol Immunol Scand. 2002; 110(11): 811-818.

24 - Tamrakar R, Yamada T, Furuta I, Cho K, Morikawa M, Yamada $\mathrm{H}$ et al. Association between Lactobacillus species and bacterial vaginosis-related bacteria, and bacterial vaginosis score in pregnant Japanese women. BMC Infect Dis. 2007; 128(7):1-8.

25 - Cole AM. Innate host defense of human vaginal and cervical mucosae. Curr Top Microbiol Immunol. 2006; 306:199-230.

26 - Pudney J, Quayle AJ, Anderson DJ. Immunological microenviroments in the human vagina and cervix: mediators of cellular immunity are concentrated in the cervical transformation zone. Biol Reprod. 2005; 73(6): 1253-1263.

27 - Ugwumadu AH. Cervical morphology in pregnancy bacterial vaginosis and the risk of preterm delivery. Ultrasound Obstet Gynecol. 2000; 15(3):174-176.

28 - Donders GG, Bosmans E, Dekeersmaecher A, Vereecken A, Van Bulck B, Spitz B. Pathogenesis of abnormal vaginal bacterial flora. Am J Obstet Gynecol. 2000; 182: 872-878.

29 - Smeltzer SC, Bare BG. Tratamento de pacientes com doenças infecciosas. In.:Brunner \& Suddarth: Tratamento de enfermagem médico-cirúrgica. 9a ed. Rio de Janeiro: Guanabara Koogan. 2002.

30 - Romero R, Chaiworapongsa T, Kuivaniemi H, Tromp $\mathrm{G}$. Bacterial vaginosis, the inflammatory response and the risk of preterm birth: a role for genetic epidemiology in the prevention of preterm birth. Am J Obstet Gynecol. 2004; 190(6): 1509-1519.

30 - Demba E, Morinson L, Van Der Loeff M, Awasana A, Gooding $\mathrm{E}$, Bailey $\mathrm{R}$ et al. Bacterial vaginosis, vaginal flora patterns and vaginal hygiene practices in patients presenting with vaginal discharges syndrome in the Gambia, West África. BMC Infect Dis. 2005; 5(12): 1-2.
31- Romero R, Mazor M, Munoz H, Gomez R, Galasso M, Sherer DM. The preterm labor syndrome. Ann NY Acad Sci. 1994; 734: 414-429.

32 - Koumans EH, Kendrick JS. Bacterial vaginosis working group preventing adverse sequelae of bacterial vaginosis: a public health program and research agenda. Sex Transm Dis. 2000; 28: 292-297.

33 - Persson E, Bergström M, Larsson PG, Moberg P, PlatzChristensen JJ, Schedvins $\mathrm{K}$ et al. Infections after hysterectomy. A prospective nationwide swedish study. The study group on infectious diseases in obstetrics and gynecology within the swedish society of obstetrics and gynecology. Acta Obstet Gynecol Scand. 1996; 75(8): 757761.

34 - Weir E. Bacterial vaginosis: more questions and answers. Disponível em: $<$ http:www.cmaj.ca/cgi/content/full/171/5/448>. Acesso em: 31 jan. 2006.

35 - Brenna SMF, Hardy EE, Zeferino LC, Namura I. Conhecimento atitude e prática do exame papanicolaou em mulheres com câncer do colo uterino. Caderno de Saúde Pública. 2001; 17(4): 909-914.

36 - Kiss H, Petricevic L, Husslein P. Prospective randomised controlled trial of an infection screening programme to reduce the rate of preterm delivery. $\mathrm{Br}$ Med J. 2004; 329(7462): 317-323.

37 - King J, Flenady V. Prophylactic antibiotics for inhibiting preterm labour with intact membranes. Cochrane Database Syst Rev. 2002; CD000246,(4).

38 - Kenyon SL, Taylor DJ, Tarnow-Mordi W. Broadspectrum antibiotics for spontaneous preterm labour: the ORACLE II randomized trial. Lancet. 2001; 357(9261): 989-994.

39 - Fachini AM, Giraldo P, Eleutério JJ, Jacyntho C, Gonçalves AK, Linhares, I. Vaginose bacteriana e trabalho de parto prematuro: uma associação não muito bem compreendida. DST J Bras Doenças Sex Transm. 2005; 17(2): 149-152.

40 - Cavalcante VLN, Miranda AT, Portugal GMP. Rastreamento de candidose vaginal durante a prevenção do câncer cérvico-uterino. DST J Bras Doenças Sex Transm. 2005; 17(1): 44-48. 
41 - Feferbaum, R. Infecção por Candida no período neonatal. In: Marcondes, E. Pediatria Básica. 1a ed. São Paulo: Savier, 1994.

42 - Lira Neto, J.B. Achados colpocitológicos em $\mathbf{1 7 8 7}$ casos de vaginites. J Bras Ginecol. 1985; 95(11,12): 529534.

43 - Wied GL, Koss LG, Reagan JW. Compendium on diagnostic cytology. 6a ed. Chicago: Tutorials of Cytology, 1998.

44 - Barros SMO. Vulvovaginites na gestação: prevalência, atualização e assistência de enfermagem obstétrica. Acta paul enferm. 1995; 8(4): 38-45.

45 - Soper D. Trichomoniasis: under control or undercontrolled?. Am J Obstet Gynecol. 2004; 190(1): 281-290.

46 - Klebanoff MA, Carey JC, Hauth JC, Hillier SL, Nugent RP, Thom EA et al. Failure of metronidazole to prevent preterm delivery among pregnant women with asymptomatic Trichomonas vaginalis infection. $\mathrm{N}$ Engl $\mathrm{J}$ Med. 2001; 345(7): 487-493.

47 - Al-Salihi FL, Curran JP, Wang JS. Neonatal Trichomonas vaginalis. Report of three cases and review of the literature. Pediatrics. 1974; 53(2): 196-200.

48 - Pereira AD, Melo NT, Belda W, Siqueira LFG, Santos MFQ, Lacaz CS. Incidência de leveduras em secreção vaginal. Rev Bras Clín Ter. 1988; 17(8): 262-266.

49 - Silveira EC, Tavenard A, Nunes E. Associação da tricomoníase com lesões pré-malignas e malignas do colo uterino. Rev Bras Anal Clin. 2000; 32(2): 111-114.

Recebido em 09 de dezembro de 2010.

Aprovado em 22 de dezembro de 2010. 